\title{
Quantification of intrusive/retraction force and moment generated during en-masse retraction of maxillary anterior teeth using mini-implants: A conceptual approach
}

\author{
A. Sumathi Felicita ${ }^{1}$
}

DOI: https://doi.org/10.1590/2177-6709.22.5.047-055.oar

Objective: The aim of the present study was to clarify the biomechanics of en-masse retraction of the upper anterior teeth and attempt to quantify the different forces and moments generated using mini-implants and to calculate the amount of applied force optimal for en-masse intrusion and retraction using mini-implants. Methods: The optimum force required for en-masse intrusion and retraction can be calculated by using simple mathematical formulae. Depending on the position of the mini-implant and the relationship of the attachment to the center of resistance of the anterior segment, different clinical outcomes are encountered. Using certain mathematical formulae, accurate measurements of the magnitude of force and moment generated on the teeth can be calculated for each clinical outcome. Results: Optimum force for en-masse intrusion and retraction of maxillary anterior teeth is 212 grams per side. Force applied at an angle of $5^{\circ}$ to $16^{\circ}$ from the occlusal plane produce intrusive and retraction force components that are within the physiologic limit. Conclusion: Different clinical outcomes are encountered depending on the position of the mini-implant and the length of the attachment. It is possible to calculate the forces and moments generated for any given magnitude of applied force. The orthodontist can apply the basic biomechanical principles mentioned in this study to calculate the forces and moments for different hypothetical clinical scenarios. Keywords: Orthodontics. Orthodontic space closure. Orthodontic anchorage procedures.

Objetivo: o objetivo do presente estudo foi explicar o funcionamento da biomecânica de retração em massa dos dentes anterossuperiores e tentar quantificar as diferentes forças e momentos gerados ao se usar mini-implantes, além de calcular a quantidade ideal de força a ser aplicada para se obter a intrusão/retração em massa ancorada em mini-implantes. Métodos: a força ideal necessária para se realizar a intrusão/retração em massa pode ser calculada por meio de fórmulas matemáticas simples. Dependendo da posição do mini-implante e da posição do acessório, a ele conectado, com relação ao centro de resistência do segmento anterior, obtêm-se desfechos clínicos diferentes. Aplicando certas fórmulas matemáticas, pode-se calcular com precisão a magnitude da força e do momento gerado nos dentes, para cada desfecho clínico. Resultados: a força ideal para se obter a intrusão/retração em massa dos dentes anterossuperiores é de 212 gramas por lado. A força aplicada em um ângulo de $5^{\circ}$ a $16^{\circ}$ em relação ao plano oclusal produz componentes de força de intrusão/retração que se encontram dentro dos limites fisiológicos. Conclusão: podem ser encontrados diferentes desfechos clínicos dependendo da posição do mini-implante e do comprimento do acessório. É possível calcular as forças e os momentos gerados para qualquer magnitude de força aplicada. Assim, o ortodontista clínico pode aplicar os princípios biomecânicos básicos apresentados nesse estudo para calcular as forças e os momentos em diferentes cenários clínicos hipotéticos.

Palavras-chave: Ortodontia. Fechamento de espaço ortodôntico. Procedimentos de ancoragem ortodôntica.

${ }^{1}$ Saveetha University, Saveetha Dental College, Department of Orthodontics and Dentofacial Orthopedics (Chennai, India).

Contact address: A. Sumathi Felicita

E-mail: sumifeli@hotmail.com
How to cite: Felicita AS. Quantification of intrusive/retraction force and moment generated during en-masse retraction of maxillary anterior teeth using mini-implants: a conceptual approach. Dental Press J Orthod. 2017 Sept-Oct;22(5):47-55. DOI: https://doi.org/10.1590/2177-6709.22.5.047-055.oar

Submitted: August 18, 2016 - Revised and accepted: January 13, 2017

» The authors report no commercial, proprietary or financial interest in the products or companies described in this article.

» Patients displayed in this article previously approved the use of their facial and intraoral photographs. 


\section{INTRODUCTION}

Space closure with mini-implant anchorage usually involves application of force by means of closed coil spring or elastic traction from the mini-implant placed between the maxillary second premolar and maxillary first molar, bilaterally ${ }^{1-7}$, to an attachment placed between the lateral incisor and canine, on a continuous archwire (Fig 1). This usually results in the application of a diagonal vector of force on the maxillary anterior teeth of both sides. This applied diagonal force vector can be resolved into an intrusive and retraction component, and its magnitude depends on the direction of applied force, in relation to the occlusal plane. This direction of applied force is determined by the length of the attachment and the height of the mini-implant from the base archwire (Fig 2). Therefore, the direction of applied force becomes more obtuse as the length of the attachment is reduced and the height of the mini-implant is increased, and vice versa.

However, retraction on a continuous archwire produces a statically indeterminate system and cannot be quantified. But if the base archwire is segmented distal to the canine on both sides, it is possible to produce a statically determinate force system that can be accurately calculated. This paper deals with a statically determinate force system. Thus, the aim of this paper is:

1. To calculate the magnitude of optimum force required for en-masse retraction using mini-implants.

2. To determine the optimum direction of applied force to produce optimum resultant forces.

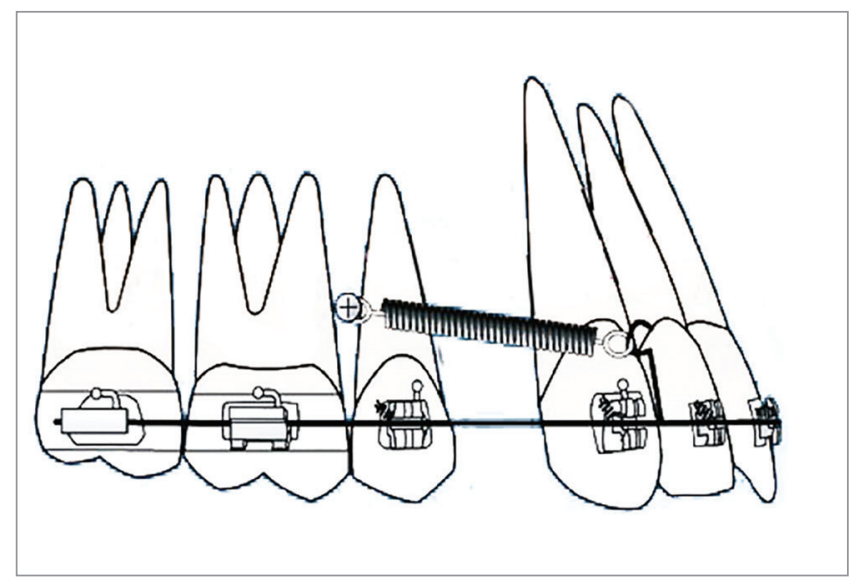

Figure 1 - Force applied from the mini-implant placed between the maxillary second premolar and first molar to an attachment soldered onto the archwire distal to the lateral incisor.
3. To quantify the magnitude of force and moment generated for any given clinical outcome.

\section{MATERIAL AND METHODS}

The direction of force application from the maxillary anterior teeth to the mini-implant can be represented using a simple mathematical model (Fig 3). This model is designed based on the parallelogram law of forces. According to the parallelogram law of vectors, a parallelogram has two adjacent sides, that represent two force vectors; and a diagonal, which is the resultant sum of the two vectors. For all practical purposes, resolution of a diagonal force in orthodontics is done with two vectors perpendicular to each other, ${ }^{9}$ and the direction of resultant force at an angle of $45^{\circ}$ to the occlusal plane (Fig 4).

According to this model, the magnitude of applied force can be calculated using the formula: ${ }^{9} \mathrm{~F}_{\mathrm{a}}=\sqrt{ }\left(\mathrm{f}_{1}^{2}+\mathrm{f}_{\mathrm{r}}^{2}\right)$.

The optimum force for simultaneous intrusion and retraction of anterior teeth $=\sqrt{ }\left(210^{2}+30^{2}\right)=\sqrt{ }(44,100+900)$ $=212.132 \mathrm{~g}$, since optimum force required to translate $\mathrm{a}$ single anterior tooth is $70 \mathrm{~g}^{8}$ and that required to intrude one anterior teeth is $10 \mathrm{~g}^{8}$.

However, in a clinical situation the force is not always applied at $45^{\circ}$ to the occlusal plane and varies depending on the length of attachment and height of the mini-implant from the occlusal plane. Hence for any given clinical situation the direction of applied force to the occlusal plane can make an angle ' $\theta$ ' which can vary from $0^{\circ}$ to $90^{\circ}$. This angle can be derived either by the direct method or indirect method.

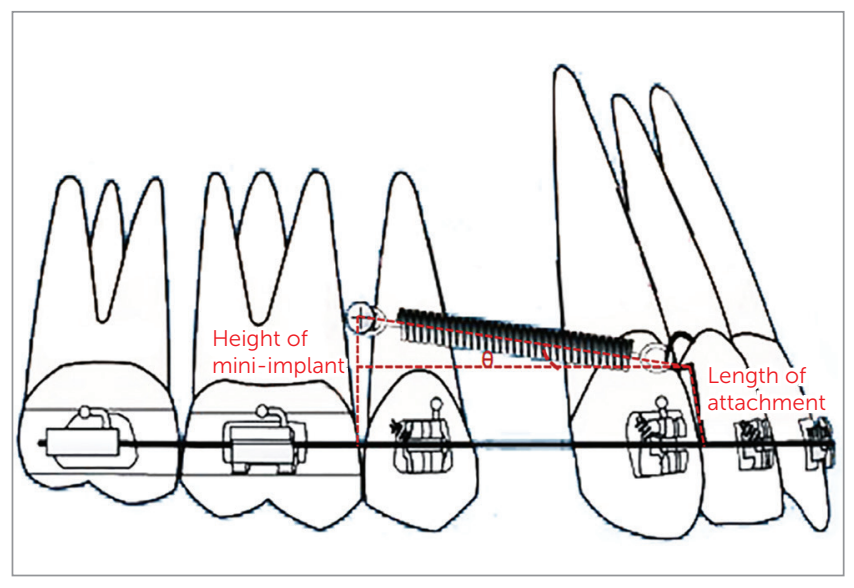

Figure 2 - Showing the angulation made by the applied force to the horizontal, depending on the height of the soldered attachment and the height of the mini-implant from the base archwire. 


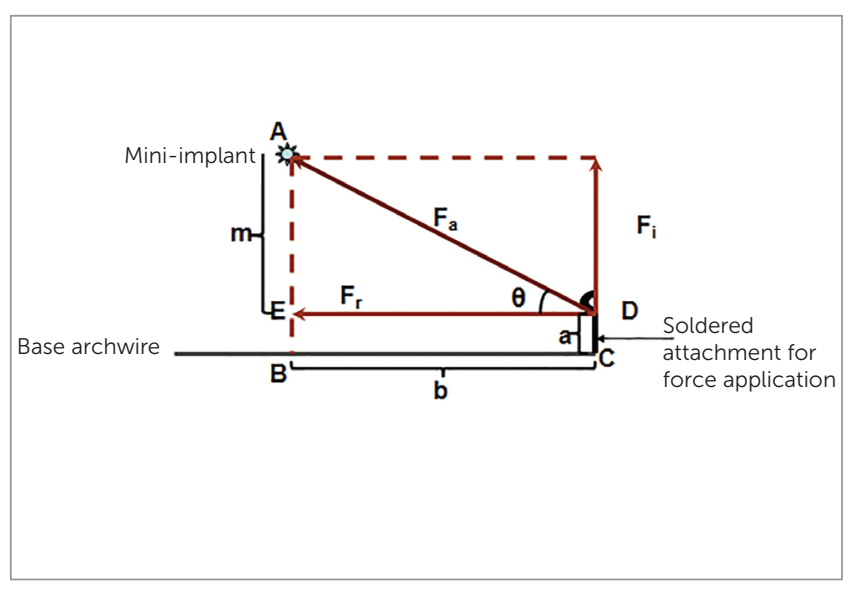

Figure 3 - Showing the parallelogram law of vectors with $f_{a}$ being the resultant force of the two individual forces $f_{i}$ and $f_{r}$

\section{Direct method}

Bend a stiff straight length 0.07 " round wire. The bent wire is adjusted such that the upper end of the bent wire is placed on the coil spring, the vertex of the bent wire is placed on the point of force application on the attachment and the lower end of the bent wire is placed parallel to the base archwire. This angulation obtained is measured to the nearest degree (Fig 5).

\section{Indirect method}

The angulation of the applied force can also be obtained from certain intraoral linear measurements. The following measurements are made, as shown in Figures 6A and 6B: $\mathrm{AE}$, denoted as ' $\mathrm{m}$ '; $\mathrm{EB}=\mathrm{DC}$, denoted as 'a'; and BC =ED, denoted as 'b' - where ' $m$ ' is the perpendicular distance in millimeters from the mini-implant to the base archwire; 'a' is the length of the attachment in millimeters from the point of attachment on the base archwire to the point of attachment of the coil spring; and ' $b$ ' is the linear horizontal distance between the perpendicular from the miniimplant to the base archwire and the attachment on the base archwire.

Now, according to Figure 6:

》 $\mathrm{AE}=\mathrm{AB}$ minus $\mathrm{EB}=\mathrm{AB}$ minus $\mathrm{DC}$ (since $\mathrm{EB}=\mathrm{DC}$ ); " $\mathrm{AED}$ is a right angled triangle with an angle $\theta$ between AD and ED. To determine ' $\theta$ ':

» $\theta=\operatorname{Cos}$ (adjacent side/hypotenuse) = Sin (opposite side $/$ hypotenuse $)=\tan$ (opposite side/ adjacent side).

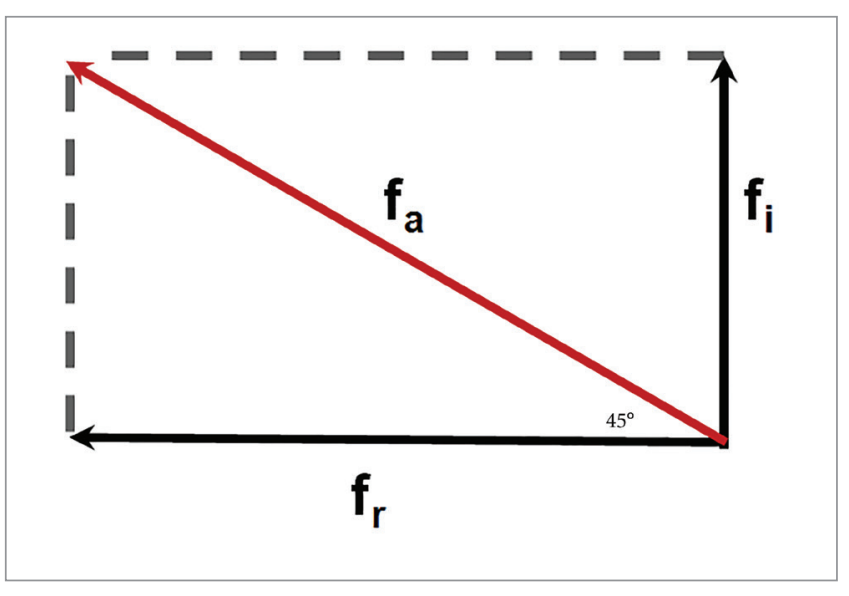

Figure 4 - Showing $f_{a}$ as the hypotenuse of a right angled triangle with the component vectors $\mathrm{f}_{\mathrm{i}}$ and $\mathrm{f}_{\mathrm{r}}$ forming the other two sides of the triangle.

Using any of the aforementioned equations the value of ' $\theta$ ' can be determined: ' $\theta$ ' gives the direction of applied force.

However, the intrusive and retraction forces generated for any given direction ' $\theta$ ' of the applied force may not be optimum, as shown in Table 1, and it is imperative to determine the optimum direction of applied force from the mini-implant to the anterior teeth.

The value of $212 \mathrm{~g}$ is the optimum force applied from the attachment on the base archwire to the mini-implant. The magnitude of applied force can be accurately measured using a Dontrix gauge (TP Orthodontics, Inc.) or a Corex gauge (Haag- Streit AG, Gartenstadstrasse 10, 3098 Koeniz, Switzerland).

Theoretically, the direction of this force can range from $0^{\circ}$ to $90^{\circ}$. Using the same mathematical model as above, the resultant forces for a clinical situation as shown in Figure 3 can be calculated. For a given clinical situation where the optimum diagonal force of $212 \mathrm{~g}$ per side is at $16^{\circ}$ to the horizontal — as determined using either the direct or the indirect method-, the retraction and intrusive force generated can be calculated as follows:

$\mathrm{F}_{\mathrm{r}}=\mathrm{F} \times \operatorname{Cos} \theta$

Retraction force $=F_{r}=212 \times \operatorname{Cos} 16$

$$
\begin{aligned}
& =212 \times 0.2756 \\
& =58.4272 \mathrm{~g}
\end{aligned}
$$

Therefore, $F_{i}=F \times \operatorname{Sin} \theta$

$$
\begin{aligned}
\mathrm{F}_{\mathrm{i}}=\text { Intrusive force } & =212 \times \operatorname{Sin} 16 \\
& =212 \times 0.9613 \\
& =203.7956 \mathrm{~g}
\end{aligned}
$$



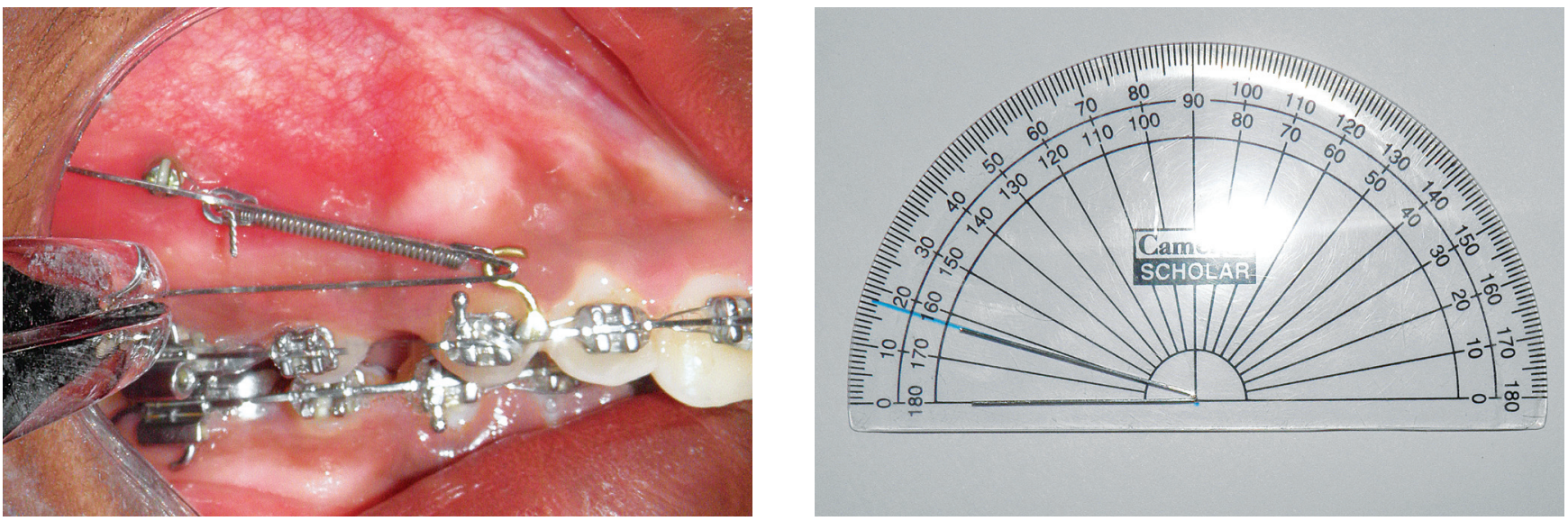

Figure 5 - Direct measurement of the angle made by the applied force to the occlusal plane.
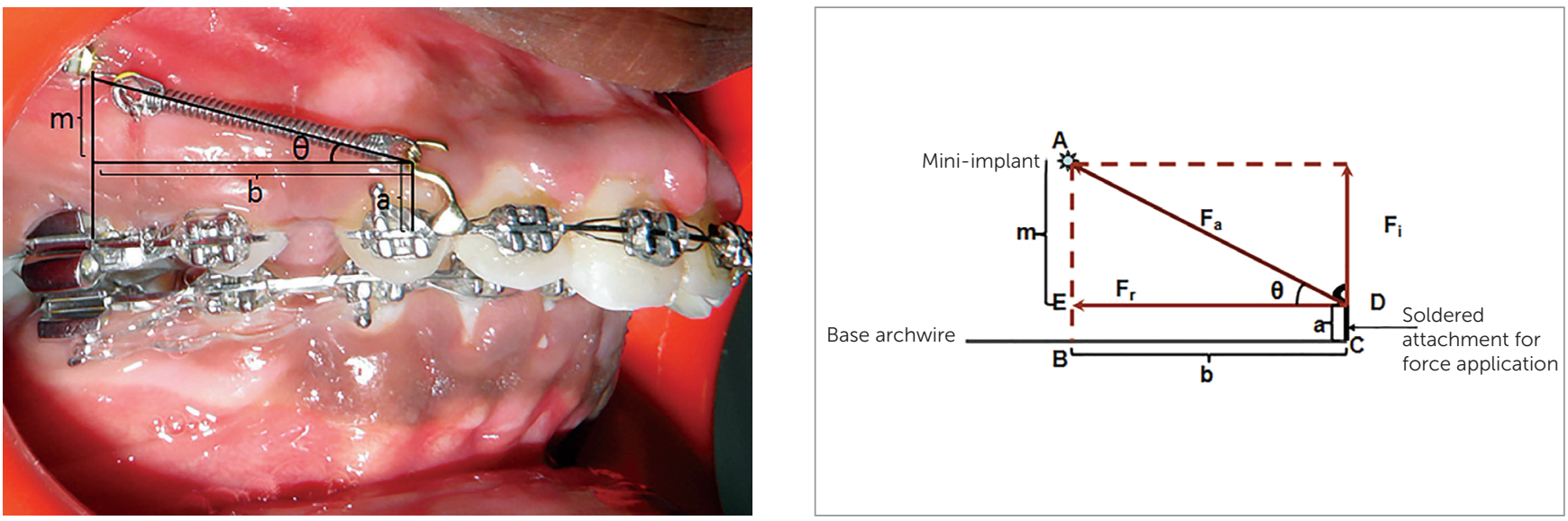

Figure 6 - Indirect measurement of the angle made by the applied force to the occlusal plane.

Table 1 gives the intrusive and retraction force generated for an optimum force of $212 \mathrm{~g}$ for different angulations. It can be noted that the intrusive component of force is beyond the physiologic limit for an angulation of $17^{\circ}$ with an intrusive force of $61.98888 \mathrm{~g}$.

The optimum force and the optimum direction of force application have now been established. But in a clinical situation the applied force does not always pass through the center of resistance of the maxillary anterior teeth and moments are generated depending on the relation between the direction of applied force and the center of resistance of the anterior teeth. The magnitude of these moments is given as:

» Moment of a given force $=$ Distance between the CRes and the point of force application $\mathrm{x}$ Force.
» The moment generated by the horizontal component of force $=$ Vertical Distance from the CRes to the point of force application $\mathrm{x}$ horizontal force (calculated retraction force at an angle of $16^{\circ}$ )

$=\mathrm{M}_{\mathrm{r}}=4.5 \mathrm{~mm} \times 204 \mathrm{~g}=918 \mathrm{~g}-\mathrm{mm}$ per side (Fig 7A). The moment generated by the vertical component of force $=$ Horizontal Distance from the CRes to the point of force application $\mathrm{x}$ vertical force (calculated intrusive force at $16^{\circ}$ )

$=M_{i}=10.5 \mathrm{~mm} \times 58 \mathrm{~g}=609 \mathrm{~g}-\mathrm{mm}$ per side (Fig 7A).

The vertical and horizontal distance was determined from the vertical and sagittal position of the CRes. The center of resistance varies from $8.1 \mathrm{~mm}$ to $14.7 \mathrm{~mm}$ from the incisal edge in the vertical direction when a sagittal force is applied on the six anterior teeth. ${ }^{10}$ The length of the attachment determines the distance 
Table 1 - The intrusive and retraction force generated for a diagonal force of 212 grams for different angulations.

\begin{tabular}{|c|c|c|}
\hline Degrees & $\begin{array}{l}\text { Intrusive force } \\
\text { (grams) }\end{array}$ & $\begin{array}{l}\text { Retraction force } \\
\text { (grams) }\end{array}$ \\
\hline 0 & 0 & 212 \\
\hline 5 & 18.4864 & 211.1944 \\
\hline 6 & 22.154 & 210.834 \\
\hline 7 & 25.8428 & 210.41 \\
\hline 8 & 29.5104 & 209.9436 \\
\hline 9 & 33.1568 & 209.3924 \\
\hline 10 & 36.8032 & 208.7776 \\
\hline 11 & 40.4496 & 208.0992 \\
\hline 12 & 44.0748 & 207.3572 \\
\hline 13 & 47.7 & 206.5728 \\
\hline 14 & 51.2828 & 205.7036 \\
\hline 15 & 54.8656 & 204.7708 \\
\hline 16 & 58.4272 & 203.7956 \\
\hline 17 & 61.9888 & 202.7356 \\
\hline 18 & 65.508 & 201.6332 \\
\hline 19 & 69.0272 & 200.446 \\
\hline 20 & 72.504 & 199.2164 \\
\hline 30 & 106 & 183.592 \\
\hline 40 & 136.2736 & 162.392 \\
\hline 50 & 162.392 & 136.2736 \\
\hline 60 & 183.592 & 106 \\
\hline 70 & 199.2164 & 72.504 \\
\hline 80 & 208.7776 & 36.8032 \\
\hline 90 & 212 & 0 \\
\hline
\end{tabular}
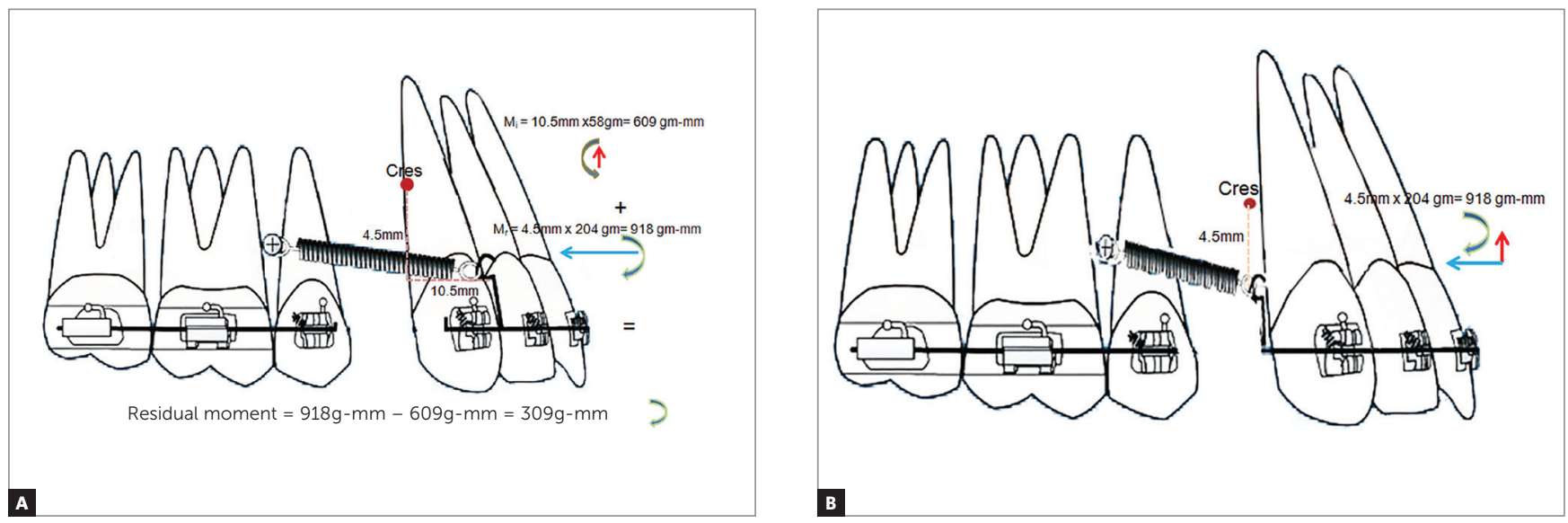

Figure 7 - A) Calculation of residual moment when the attachment is placed between the lateral incisor and canine. B) Calculation of moment when the attachment is placed distal to the canine. 


\section{RESULTS}

The amount of 212 grams is the optimum force required for en-masse intrusion and retraction of anterior teeth using mini-implants.

However, the resultant forces are optimum when the direction of force application ranges from $5^{\circ}$ to $16^{\circ}$.

A residual moment of $309 \mathrm{~g}$ was produced when an optimum force of $212 \mathrm{~g}$ was applied at $16^{\circ}$ to the occlusal plane when the attachment was placed between the lateral incisor and canine.

A residual clockwise moment of $918 \mathrm{~g}$ was produced when an optimum force of $212 \mathrm{~g}$ was applied at $16^{\circ}$ to the occlusal plane when the attachment was placed distal to the canine.

The residual moment generated is definitely smaller when the attachment is placed between the lateral incisor and canine, as compared to that placed distal to the canine.

\section{DISCUSSION}

The different clinical outcomes encountered during en-masse retraction using mini-implants can be classified into three types, depending on the relation between the point of force application and the center of resistance of the maxillary anterior teeth.

" Outcome I: The point of force application lies apical to the center of resistance of the maxillary anterior teeth (There are two sub-types, depending on the relation between the mini-implant and the point of force application).

"Outcome IA: When the point of force application is located apical to the center of resistance of the maxillary anterior teeth and occlusal to the mini-implant, a counter-clockwise moment is generated along with an intrusive and retraction component of force (Fig 8A). This counter-clockwise moment will result in labial flaring of the teeth, with bite-opening augmenting the effect of the mild intrusive force component. The magnitude of retraction force component should be sufficient to overcome the flaring of the anterior teeth prior to retraction.

» Outcome IB: When the point of force application is apical to the center of resistance and the mini-implant, a large counter-clockwise moment is generated, with an extrusive and retraction component of force (Fig 8B). The large counter-clockwise moment can cause severe labial flaring with associated bite opening, which may be partly negated by the mild extrusion caused by the extrusive component of force. Hence only retraction of teeth can be expected. The retraction force has to overcome the labial flaring of the teeth to allow them to be retracted.

" Outcome II: The point of force application lies on the CRes of the maxillary anterior teeth; if the point of force application lies on the center of resistance of the maxillary anterior teeth, bodily movement of maxillary anterior teeth occurs (there are the following three situations, depending on the position of the mini-implant and the attachment).

" Outcome IIA: If the mini-implant is apical to the center of resistance, an intrusive and retraction force is generated, without any moment (Fig 9A). True intrusion and translation can be expected.

» Outcome IIB: If the mini-implant is at the level of center of resistance, only a retraction force is generated, without any moment (Fig 9B). If the implant is in the same plane of the center of resistance and the force passes through the center of resistance, only translation with no intrusion will take place.

» Outcome IIC: If the mini-implant is occlusal to the center of resistance, an extrusive and retraction force is generated, without any moment (Fig 9C). True extrusion and translation will occur.

» Outcome III: The point of force application lies occlusal to the CRes of the maxillary anterior teeth (there are the following three types, depending on the relation between the mini-implant and the point of force application).

" Outcome IIIA: If the point of force application is occlusal to the mini-implant and the center of resistance of the maxillary anterior teeth and apical to the base archwire, an intrusive and retraction force is generated along with a clockwise moment (Fig 10A). This will result in lingual tipping of the teeth, with bite deepening. However, this may be negated by the intrusive force component. Therefore, only retraction of the teeth will be attained.

Outcome IIIB: If the point of force application lies apical to the mini-implant and occlusal to the center of resistance of the maxillary anterior teeth, but apical to the occlusal plane, an extrusive and retraction force along with a clockwise moment is generated (Fig 10B). This extrusive force along with a clockwise moment can cause bite deepening in the anterior region during retraction. 

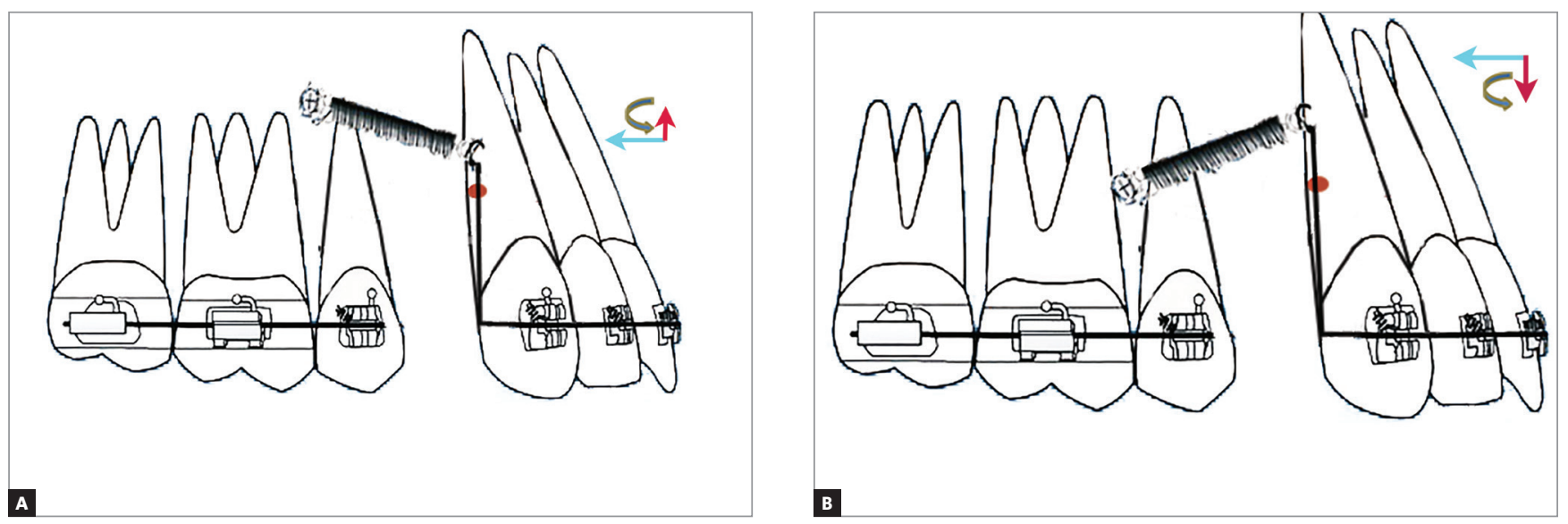

Figure 8 - A) Outcome IA: The point of force application is located apical to the CRes of the maxillary anterior teeth but occlusal to the mini-implant. B) Outcome IB: The point of force application is located apical to the CRes of the maxillary anterior teeth and also apical to the mini-implant.

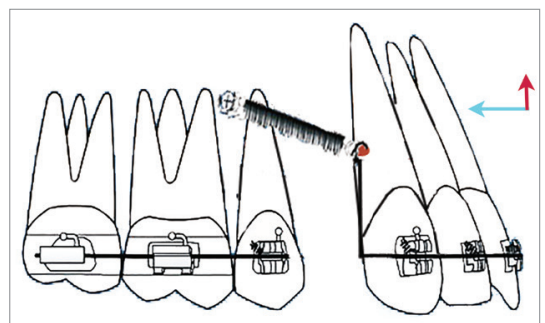

A

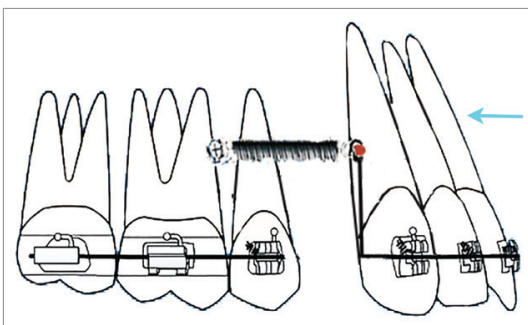

B

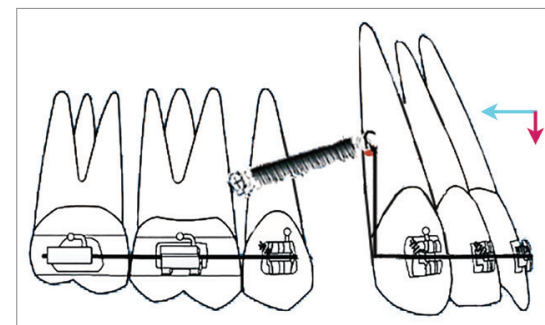

C

Figure 9 - A) Outcome IIA: The point of force application lies on the CRes of the maxillary anterior teeth occlusal to the mini-implant. B) Outcome IIB: The point of force application lies on the CRes of the maxillary anterior teeth at the level of the mini-implant. C) Outcome IIC: The point of force application lies on the CRes of the maxillary anterior teeth apical to the mini-implant.

" Outcome IIIC: If the point of force application is at the level of the occlusal plane and occlusal to the center of resistance of the maxillary anterior teeth, a large clockwise moment is generated. A greater intrusive force is generated along with a retraction force (Fig 10C).

Since the point of force application is far away from the CRes of the maxillary anterior teeth, a greater clockwise moment is generated. However, the intrusive force may not be sufficient to completely negate the bite deepening tendency that may occur due to the clockwise moment, and bite deepening may occur. Application of force closer to the center of resistance of the maxillary anterior teeth will reduce the moment. This is often beneficial. Hence, Outcome IIIC may not be appropriate from a biomechanical stand point.

Thus, it can be inferred that if a greater intrusive force component is desired, the force should be applied away from the occlusal plane, and vice versa. If a greater retraction force component is required, applied force should be placed closer to the occlusal plane, and vice versa. It can be stated that pure translation and true intrusion or extrusion of the teeth can be attained only for the configuration in Outcome II. In Outcomes I and III, tipping is expected to occur depending on the magnitude of moment generated. The clinician can adjust the force magnitude according to the intended type of orthodontic movement.

A number of studies ${ }^{13-18}$ have been done on the center of resistance of the maxillary anterior teeth, and a large variability in the position of the center of resistance was recorded over time, even for the same tooth. As a result, close monitoring of the dental movement is required.

This study in its entirety is a theoretical one and is based on well-known mathematical and physical formulae. Application of these situations in clinical practice 

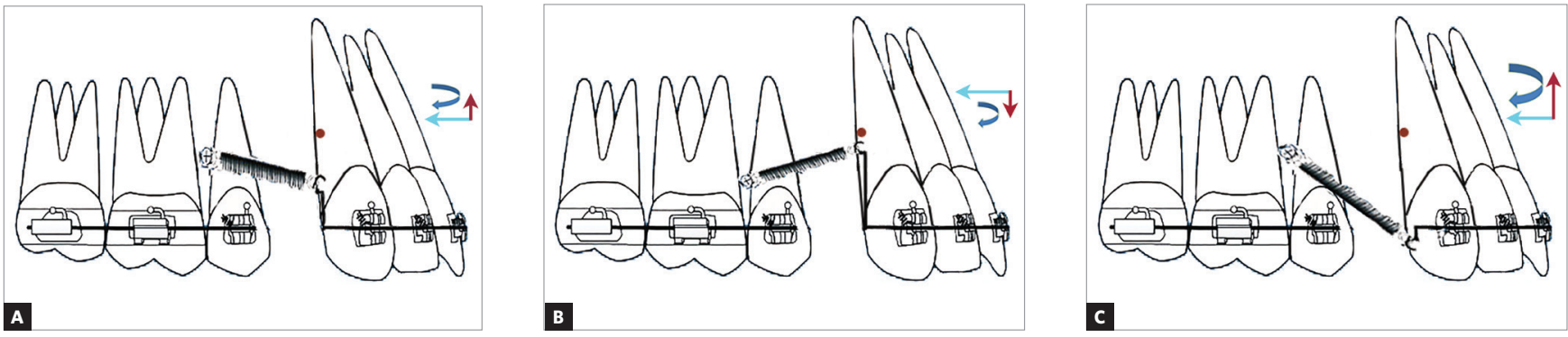

Figure 10 - A) Outcome IIIA: The point of force application lies occlusal to the mini-implant and the CRes of the maxillary anterior teeth. B) Outcome IIIB: The point of force application lies apical to the mini-implant occlusal to the CRes of the maxillary anterior teeth. C) Outcome IIIC: The point of force application lies occlusal to the mini-implant but away from the CRes of maxillary anterior teeth slightly occlusal to the base archwire.

depends on a number of factors like variability in the position of center of resistance, bone heights, root lengths, patient biology, root surface area, binding friction, etc. It would be much more relevant to the practicing orthodontist to apply the basic biomechanical principles mentioned in this study to calculate the forces/moments prior to the commencement of treatment.

The length and position of the attachment is important in determining the magnitude of moment generated. The length of attachment can be limited by the depth of the vestibule, as a relatively long attachment can cause soft tissue irritation and ulceration. It is better to place the attachment between the lateral incisor and canine as lesser residual forces are produced, in comparison to that placed distal to the canine.

It is to be noted that all the mechanics discussed above are for statically determinate system. If the same principles are applied during en-masse retraction on a continuous archwire, a change in the inclination of the occlusal plane can occur because of the moments pro- duced. When retraction using mini-implants in done on a continuous archwire, it may not be possible to accurately predict the magnitude of force generated and its effect on the dentition.

\section{CONCLUSION}

1. Optimum force for en-masse intrusion and retraction using mini-implants is $212 \mathrm{~g}$ per side.

2. Forces applied at an angle of $5^{\circ}$ to $16^{\circ}$ to the occlusal plane produces force components within the physiologic limit.

3. An attachment placed between the lateral incisor and the canine result in lesser residual moments and is therefore a better biomechanically efficient system.

4. Different clinical outcomes will result depending on the height of the mini-implant and the length of the attachment, which will generate an intrusive/extrusive and retraction component of force along with a clockwise or counter-clockwise moment, depending on its relation to the center of resistance of the anterior teeth. 


\section{REFERENCES}

1. Park HS, Jeong $\mathrm{SH}$, Kwon OW. Factors affecting the clinical success of screw implants used as orthodontic anchorage. Am J Orthod Dentofacial Orthop. 2006 July;130(1):18-25.

2. Kyung HM, Park HS, Bae SM, Sung JH, Kim IB. Development of orthodontic micro-implants for intraoral anchorage. J Clin Orthod. 2003 June;37(6) 321-8; quiz 314.

3. Moon $\mathrm{CH}$, Lee DG, Lee HS, Im JS, Baek SH. Factors associated with the success rate of orthodontic miniscrews placed in the upper and lower posterior buccal region. Angle Orthod. 2008 Jan:78(1):101-6.

4. Baumgaertel S, Razavi MR, Hans MG. Mini-implant anchorage for the orthodontic practitioner. Am J Orthod Dentofacial Orthop. 2008 Apr;133(4):621-7.

5. Herman RJ, Currier GF, Miyake A. Mini-implant anchorage for maxillary canine retraction: a pilot study. Am J Orthod Dentofacial Orthop. 2006 Aug:130(2):228-35.

6. Chung KR, Nelson G, Kim SH, Kook YA. Severe bidentoalveolar protrusion treated with orthodontic microimplant-dependent en-masse retraction Am J Orthod Dentofacial Orthop. 2007 July:132(1):105-15

7. Garfinkle JS, Cunningham LL Jr, Beeman CS, Kluemper GT, Hicks EP, Kim MO. Evaluation of orthodontic mini-implant anchorage in premolar extraction therapy in adolescents. Am J Orthod Dentofacial Orthop. 2008 May:133(5):642-53.

8. Proffit WR, Fields HW. Contemporary orthodontics. 3rd ed. Saint Louis: Mosby; 2000

9. Gross D, Hauger W, Schröder J, Wall W, Rajapakse N, Schroder JR, et al. Engineering Mechanics 1: Statics. 1st ed. Berlin: Springer-Verlag; 2013.

10. Reimann S, Keilig L, Jäger A, Bourauel C. Biomechanical finite-element investigation of the position of the centre of resistance of the upper incisors. Eur J Orthod. 2007 June:29(3):219-24. Epub 2007 Feb 22
11. Pedersen E, Isidor F, Gjessing P. Andersen K. Location of centres of resistance for maxillary anterior teeth measured on human autopsy material. Eur J Orthod. 1991 Dec;13(6):452-8

12. Ash N. Wheeler's Dental anatomy, physiology and occlusion. 8th ed. Saint Louis: Saunders; 2003

13. Vanden Bulcke MM, Dermaut LR, Sachdeva RC, Burstone CJ. The center of resistance of anterior teeth during intrusion using the laser reflection technique and holographic interferometry. Am J Orthod Dentofacial Orthop. 1986 Sept; $90(3): 211-20$

14. Vanden Bulcke MM, Burstone CJ, Sachdeva RC, Dermaut LR. Location of the centers of resistance for anterior teeth during retraction using the laser reflection technique. Am J Orthod Dentofacial Orthop. 1987 May; $91(5): 375-84$

15. Choy K, Kim KH, Burstone $\mathrm{CJ}$. Initial changes of centres of rotation of the anterior segment in response to horizontal forces. Eur J Orthod. 2006 Oct;28(5):471-4. Epub 2006 Aug 17

16. Jeong GM, Sung SJ, Lee KJ, Chun YS, Mo SS. Finite element investigation of the center of resistance of the maxillary dentition. Korean $\mathrm{J}$ Orthod. 2009:39(2):83-94.

17. Lee HK, Chung KR. The vertical location of the center of resistance for maxillary six anterior teeth during retraction using three dimensional finite element analysis. Korean J Orthod. 2001;31(4):425-38.

18. Sia S, Koga Y, Yoshida N. Determining the center of resistance of maxillary anterior teeth subjected to retraction forces in sliding mechanics: an in vivo study. Angle Orthod. 2007 Nov:77(6):999-1003. 